\title{
The effect of nicotinamide adenine dinucleotide phosphate oxidase 4 on migration and invasion of fibroblast-like synoviocytes in rheumatoid arthritis
}

Ha-Reum Lee ${ }^{1,2+}$ (D), Su-Jin Yoo ${ }^{2+}$ (D) Jinhyun $\mathrm{Kim}^{2}$ (D), In Seol Yoo ${ }^{2}$, Chan Keol Park ${ }^{2}$ and Seong Wook Kang ${ }^{1,2^{*}}$ (D)

\begin{abstract}
Background: Reactive oxygen species (ROS) regulate the migration and invasion of fibroblast-like synoviocytes $(F L S)$, which are key effector cells in rheumatoid arthritis (RA) pathogenesis. Nicotinamide adenine dinucleotide phosphate oxidase 4 (NOX4) induces ROS generation and, consequently, enhances cell migration. Despite the important interrelationship between RA, FLS, and ROS, the effect of NOX4 on RA pathogenesis remains unclear.

Methods: FLS isolated from RA $(n=5)$ and osteoarthritis $(\mathrm{OA}, n=5)$ patients were stimulated with recombinant interleukin 17 (IL-17; $10 \mathrm{ng} / \mathrm{ml})$ and tumor necrosis factor alpha (TNF-a; $10 \mathrm{ng} / \mathrm{ml})$ for $1 \mathrm{~h}$. Cell migration, invasion, adhesion molecule expression, vascular endothelial growth factor (VEGF) secretion, and ROS expression were examined. The mRNA and protein levels of NOX4 were analyzed by RT-qPCR and western blotting, respectively. The NOX4 inhibitor GLX351322 and NOX4 siRNA were used to inhibit NOX4 to probe the effect of NOX4 on these cellular processes.

Results: Migration of RA FLS was increased 2.48-fold after stimulation with IL-17 and TNF-a, while no difference was observed for OA FLS. ROS expression increased in parallel with invasiveness of FLS following cytokine stimulation. When the expression of NOX was examined, NOX4 was significantly increased by 9.73 -fold in RA FLS compared to unstimulated FLS. Following NOX4 inhibition, cytokine-induced vascular cell adhesion molecule 1 (VCAM1), VEGF, and migration and invasion capacity of RA FLS were markedly decreased to unstimulated levels.

Conclusion: NOX4 is a key contributor to cytokine-enhanced migration and invasion via modulation of ROS, VCAM1, and VEGF in RA FLS.

Keywords: Rheumatoid arthritis, Osteoarthritis, Fibroblast-like synoviocytes, Reactive oxygen species, NADPH, NOX4, VCAM1, VEGF
\end{abstract}

\footnotetext{
* Correspondence: kangsw@cnuh.co.kr

${ }^{\dagger}$ Ha-Reum Lee and Su-Jin Yoo contributed equally to this work.

${ }^{1}$ Research Institute for Medical Sciences, Chungnam National University School of Medicine, 266 Munhwaro, Daejeon, Republic of Korea

${ }^{2}$ Division of Rheumatology, Department of Internal Medicine, Chungnam National University Hospital, 282 Munhwaro, Daejeon 35015, Republic of Korea
}

(c) The Author(s). 2020 Open Access This article is licensed under a Creative Commons Attribution 4.0 International License, which permits use, sharing, adaptation, distribution and reproduction in any medium or format, as long as you give appropriate credit to the original author(s) and the source, provide a link to the Creative Commons licence, and indicate if changes were made. The images or other third party material in this article are included in the article's Creative Commons. licence, unless indicated otherwise in a credit line to the material. If material is not included in the article's Creative Commons licence and your intended use is not permitted by statutory regulation or exceeds the permitted use, you will need to obtain permission directly from the copyright holder. To view a copy of this licence, visit http://creativecommons.org/licenses/by/4.0/. The Creative Commons Public Domain Dedication waiver (http://creativecommons.org/publicdomain/zero/1.0/) applies to the data made available in this article, unless otherwise stated in a credit line to the data. 


\section{Key message}

- NOX4 mediated a differential response to IL-17 and TNF- $\alpha$ stimulation in RA FLS compared to OA FLS

- NOX4 was increased by cytokine exposure and was required for RA FLS migration and invasion via increased expression of VCAM1 and VEGF

\section{Background}

Rheumatoid arthritis (RA) is a systemic autoimmune disease that is characterized by joint inflammation and bone destruction $[1,2]$. During RA pathogenesis, there is excessive immune cell infiltration into synovial joints, stimulating other immune cells, endothelial cells, and fibroblastlike synoviocytes (FLS) [3]. Activated FLS can cause synovial hyperplasia in the joint, attach to and invade the cartilage surface, cause destruction of the cartilage and bone, and activate immune responses [4]. Although migration and invasion of FLS play important roles in the initiation and development of RA, these processes are induced by diverse factors through complex pathways [5].

Reactive oxygen species (ROS), which are more abundant in RA patients than in controls, are considered to be a significant contributor to RA pathogenesis $[6,7]$. ROS act as signaling molecules to modulate cell migration, proliferation, survival, and homeostasis [8]. Although a certain amount of ROS is essential for cell protection, excessive oxidative stress contributes to inflammation, cancer, aging, and autoimmune diseases. Most intracellular ROS are generated from mitochondria and catalyzed by the enzyme complex nicotinamide adenine dinucleotide phosphate (NADPH) oxidase (NOX) $[9,10]$. There are seven of NOX proteins: NOX1-5 and DUOX1-2. Notably, NOX4 induces ROS generation and cell migration in human lung endothelial cells [11]. Recently published data suggest that the proangiogenic factor leptin triggers the migration and invasion of RA FLS via elevated ROS generation [12]; however, the specific mechanism of NOX4 in FLS invasion remains to be fully characterized in RA.

In this study, we induced pro-inflammatory conditions in FLS using recombinant interleukin 17 (IL-17) and tumor necrosis factor alpha (TNF- $\alpha$ ) treatment, as these cytokines are critical in RA pathogenesis rather than OA $[13,14]$. The pro-inflammatory cytokine IL-17 is highly expressed in RA synovium and directly stimulates FLS activation [15] while TNF- $\alpha$ inhibition is an effective universal therapy option for RA treatment. Because active migratory phenotype and strong cartilage invasiveness are unique characters of RA FLS [16], OA FLS were used as control. Actually, the primary faulty of OA is caused by cartilage rather than synovium in clinical outcome [17]. OA FLS have been widely used for comparison with RA FLS. Here, we investigated the effects of IL-
17 and TNF- $\alpha$ on migration and invasion of FLS isolated from patients with RA and OA and further explored the effects of NOX4 inhibition in the pathogenesis of RA.

\section{Methods}

Human subjects and ethics statement

Synovial tissues were obtained from 5 female RA patients (average age $61.6 \pm 1.67$ years) and 5 female OA patients (average age $64.8 \pm 16.10$ years) who were undergoing synovectomy or joint replacement. The diagnosis of RA conformed to the College of Rheumatology (ACR)/European League Against Rheumatism (EULAR) 2010 classification criteria [18]. After removing fat and fibrous tissues, the synovium was cut into small pieces and incubated with $0.1 \%$ collagenase (Sigma-Aldrich) in Dulbecco's modified Eagle's medium (DMEM) at $37^{\circ} \mathrm{C}$ for $3 \mathrm{~h}$. Cells were cultured in DMEM supplemented with $10 \%$ fetal bovine serum (FBS, Gibco) and maintained in a $5 \% \mathrm{CO}_{2}$ incubator at $37{ }^{\circ} \mathrm{C}$. FLS were used for experiments after four to six passages. This study was performed according to the recommendations of the Declaration of Helsinki and approved by the Institutional Review Board of Chungnam National University Hospital (CNUH 2015-10-052).

\section{Transwell migration and Matrigel invasion assay}

FLS were cultured in serum-free media for $5 \mathrm{~h}$. Following pre-incubation with or without NOX4 inhibitor (GLX351322, MedKoo Biosciences) for $1 \mathrm{~h}$, RA FLS were stimulated with recombinant IL-17 $(10 \mathrm{ng} / \mathrm{ml}$, Peprotech) and TNF- $\alpha(10 \mathrm{ng} / \mathrm{ml}$, Peprotech) for $1 \mathrm{~h}$. For the transwell migration assay, cells were centrifuged and loaded onto transwell filters with an $8-\mu \mathrm{m}$ pore (Corning) positioned on top of the migration chamber for 23 h. DMEM containing 10\% FBS was transferred to the bottom chamber of the transwell plate as a chemoattractant. For the invasion assay, transwell filters were preincubated with Matrigel (Corning) at $37^{\circ} \mathrm{C}$ for $1 \mathrm{~h}$. Then, transwells were incubated at $37^{\circ} \mathrm{C}$ for 3 days, fixed with $100 \%$ methanol, and stained with crystal violet (Sigma-Aldrich). Non-migrating cells on the top membrane surface were removed by washing with PBS and cotton swabs. Invaded cells were counted in five random fields per sample under an inverted microscope (magnification, $\times 100 ; 0.55$ numerical aperture dry objective; scale bar, $100 \mu \mathrm{m}$; Olympus). For quantification, the crystal violet dye was eluted with $0.1 \%$ sodium dodecyl sulfate (SDS) and quantitated using a Sunrise absorbance reader (Tecan) at $595 \mathrm{~nm}$.

\section{Flow cytometric analysis}

To analyze the intrinsic surface expressions of IL-17 or TNF receptors, FLS were stained using APC-conjugated anti-human CD217 (IL-17Ra; Invitrogen), BV421 antihuman CD120b (TNF Receptor Type II; BD Biosciences), 
and mouse anti-human CD120a (TNF Receptor Type I; BD Biosciences) with FITC-conjugated anti-mouse IgG secondary antibody (BD Biosciences).

FLS cultures were incubated with serum-free media for $5 \mathrm{~h}$ and then stimulated with recombinant IL-17 and TNF- $\alpha$ for $1 \mathrm{~h}$. Culture media was changed, and the cells were incubated with FITC-conjugated anti-human vascular cell adhesion protein 1 (VCAM1; BD Biosciences), $\mathrm{PE}-\mathrm{Cy}^{\mathrm{Tw}} 5$-conjugated anti-human intercellular adhesion molecule 1 (ICAM1; BD Biosciences), and PE-Cy ${ }^{\mathrm{mm}} 7$-conjugated anti-human neural cell adhesion molecule 1 (NCAM1; BD Biosciences). To detect ROS levels, cells were stained with MitoSOX ${ }^{\mathrm{mm}}$ Red mitochondrial superoxide indicator (Invitrogen) according to the manufacturer's instructions. Cells were analyzed with a FACSCantoII flow cytometer (BD Biosciences), and data were processed with FlowJo software (Tree Star).

\section{Wound migration assay}

When FLS cultures were approximately $90 \%$ confluent, cells were incubated with serum-free media for $5 \mathrm{~h}$. FLS monolayers were wounded with pipette tips and treated with recombinant IL-17 and TNF- $\alpha$ for $1 \mathrm{~h}$. Wound closure was monitored and photographed at 0 and $24 \mathrm{~h}$ with a Olympus inverted microscope (magnification, $\times 100$; 0.55 numerical aperture dry objective; scale bar, $100 \mu \mathrm{m}$ ). To quantify the migrated cells, pictures of the initial wounded monolayers were compared with the corresponding pictures of cells at the end of the incubation.

\section{Enzyme-linked immunosorbent assay (ELISA)}

VEGF concentrations were measured using ELISA kits for human VEGF (R\&D Systems) according to the manufacturers' instructions. VEGF levels were estimated by interpolation from a standard curve generated using a Sunrise absorbance reader (Tecan) at $450 \mathrm{~nm}$.

\section{Real-time PCR and RT-PCR}

Total RNA was extracted using TRI Reagent (Molecular Research Center), according to the manufacturer's instructions. Extracted RNA was used in reverse transcription reactions with ReverTra Ace ${ }^{\circ}$ qPCR RT Master Mix (TOYOBO) according to the manufacturer's instructions. SYBR $^{\circ}$ Green Realtime PCR Master Mix (TOYOBO) was used for real-time PCR analysis of cDNA according to the manufacturer's instructions. The primers were synthesized by Bioneer (see Table 1 for primer sequences). Thermal cycling conditions were as follows: initial denaturation at $95^{\circ} \mathrm{C}$ for $5 \mathrm{~min}, 40$ cycles of $95^{\circ} \mathrm{C}$ for $10 \mathrm{~s}, 60^{\circ} \mathrm{C}$ for $15 \mathrm{~s}$, and $72^{\circ} \mathrm{C}$ for $20 \mathrm{~s}$. A melting step was performed by raising the temperature from $72{ }^{\circ} \mathrm{C}$ to $95^{\circ} \mathrm{C}$ after the last cycle. Thermal cycling was conducted on a CFX Connect Real-Time PCR Detection System machine (Bio-Rad Laboratories). The target gene expression levels are shown as a ratio in comparison with the levels of glyceraldehyde 3phosphate dehydrogenase (GAPDH) in in the same sample via calculation of the cycle threshold $(\mathrm{Ct})$ value. The relative expression levels of target genes were calculated by the $2^{-\Delta \Delta C T}$ relative quantification method.

For RT-PCR, the synthesized cDNA was mixed with AccuPower ${ }^{\circ}$ RT PreMix (Bioneer) and 10 pmol of each specific PCR primer following the manufacturer's protocol. Amplified products were separated on 1\% agarose gels, stained with Midori green advance (NIPPON Genetics), and photographed under UV illumination using a GelDoc system (Bio-Rad Laboratories).

\section{Western blot analysis}

Cells were ruptured on ice using a RIPA lysis kit (ATTO Corporation), lysates were clarified by centrifugation, and samples were analyzed by sodium dodecyl sulfatepolyacrylamide gel electrophoresis (SDS-PAGE). Proteins were transferred onto polyvinylidene (PVDF) membranes (Bio-Rad), which were then incubated with antibodies against NOX4 (1/1000 dilution; Abcam), $\beta$-actin (1/2000 dilution; Sigma-Aldrich), PI3K $\delta$ (1/1000 dilution; Cell Signaling Technology), and GAPDH (1/3000 dilution; Cell Signaling Technology) overnight at $4{ }^{\circ} \mathrm{C}$. After washing with $\mathrm{PBS}-\mathrm{T}$, membranes were stained with peroxidase-

Table 1 Primers used for PCR

\begin{tabular}{lll}
\hline & Sense primer & Antisense primer \\
\hline NOX1 & GTTTACCGCTCCCAGCAGAA & GGATGCCATTCCAGGAGAGAG \\
NOX3 & CAAGATGCGTGGAAATACCTAAGAT & TCCCTGCTCCCACTAACATCA \\
NOX4 & ACCGTGGAGGAGGCAATTAGACAA & CAGGTTGAAGAAATGCGCCACGAT \\
NOX5 & CTCAGCGGAATCAATCAGCTGTG & AGAGGAACACGACAATCAGCCTTAG \\
DUOX1 & ATCAAGCGGCCCCTTTTTTCAC & CTCATTGTCACACTCCTCGACAGC \\
p22phox(CYBA) & ATCACGCAGCTCTGTGTCAA & AGGACAGATCATATCCTGGCT \\
p67phox(NCF2) & CGCTGGCGTCCGCCTGATCCTCA ACACCGCCAGTAGGTAGAT \\
GAPDH & ATCAGCCTCTGGAATGAAGGGG & GCAGCCAATGTTGAAGCAAATCC \\
\hline
\end{tabular}


conjugated goat anti-rabbit IgG (Abcam) or peroxidaseconjugated rabbit anti-mouse IgG (Abcam). Target proteins were then detected using the chemiluminescent HRP Substrate (Thermo Fisher Scientific).

\section{siRNA transfection}

Specific siRNA targeting NOX4 was purchased from Santa Cruz Biotechnology (sc-41586). Cells were transfected with lipofectamine transfection reagent (Invitrogen) and the indicated siRNA duplex targeting constructs. After incubation for $24 \mathrm{~h}$, downregulation of target expression was evaluated by RT-PCR and western blot analysis.

\section{Statistical analysis}

Statistical analysis was performed using the paired Student's $t$ test in SPSS 18.0. $P$ values $<0.05$ were considered statistically significant.

\section{Results}

Increased migration and invasion in RA FLS

Migration of activated FLS mediates bone damage in RA progression via invasion through the cartilage [19]. We therefore investigated whether RA FLS have increased cell migration in response to stimulation with IL-17 and TNF- $\alpha$. Following treatment with IL-17 and TNF- $\alpha$ for $1 \mathrm{~h}$, migration of FLS from patients with RA and OA was examined using a transwell chamber assay. When RA FLS were stimulated with or without IL-17 or TNF$\alpha$, cell migration was powerfully enhanced by IL-17 and TNF- $\alpha$ together (Fig. 1a, b). To exclude the intrinsic difference in levels of cytokine receptors between RA and OA FLS, we evaluated the expression of cytokine receptors on FLS. There was no difference in the expression of IL-17 and TNF receptors between RA and OA (Fig. 1c). Cell migration was increased by 2.48 -fold in RA FLS stimulated with cytokines compared to those without stimulation $(2.48 \pm 0.50)$, while cell migration did not differ for OA FLS in response to cytokine stimulation (1.01 \pm 0.18 ; Fig. $1 d$, e). This differential migration in response to IL-17 and TNF- $\alpha$ was confirmed using a scratch assay in which cell movement into the wounded area was markedly increased in RA compared to OA cultures (Fig. 1f). When cell invasion was analyzed using a Matrigel-coated transwell membrane, IL-17 and TNF- $\alpha$

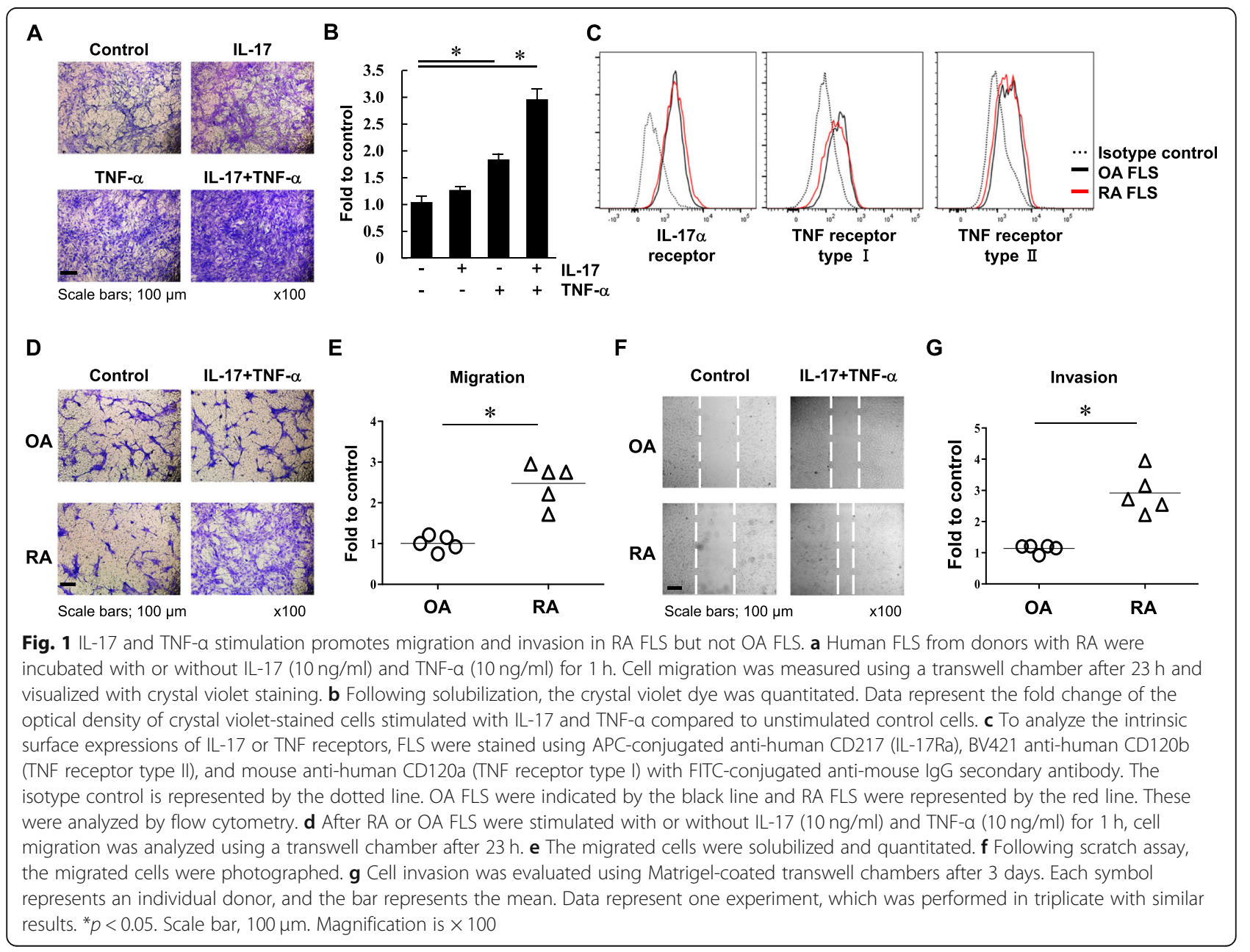


stimulation significantly enhanced the invasion ability of RA FLS compared to unstimulated RA FLS controls $(2.92 \pm 0.67$, Fig. $1 \mathrm{~g})$. Invasion by OA FLS were not changed following cytokine treatment $(1.14 \pm 0.12)$. These data indicate that RA FLS have increased cell migration and invasion in response to IL-17 and TNF- $\alpha$ stimulation than OA FLS.

Higher cytokine-induced expression of VCAM1, VEGF, and ROS in RA FLS than in OA FLS

The joint angiogenic process is mediated by various factors, such as cell adhesion molecules, cytokines/chemokines, and proteases [20]. Adhesion molecules, such as VCAM1, play a critical role in FLS migration and mediate joint inflammation and destruction [21]. We thus determined whether IL-17 and TNF- $\alpha$ promote increased expression of adhesion molecules in RA and OA FLS. Cells were incubated with IL-17 and TNF- $\alpha$ for $1 \mathrm{~h}$, and surface expression of VCAM1, ICAM1, and NCAM1 were analyzed after $23 \mathrm{~h}$. VCAM1, ICAM1, and NCAM1 were increased by nearly 3 -fold in OA FLS following cytokine exposure, while expression of these adhesion molecules in RA FLS were significantly increased by 5 - to 8 -fold following cytokine stimulation (Fig. 2a). The angiogenic growth factor VEGF was also examined in FLS following exposure to IL-17 and TNF- $\alpha$. Under basal conditions, VEGF exhibited a 3-fold increase in RA FLS compared to OA FLS; however, cytokine stimulation upregulated VEGF similarly in both RA and OA FLS (Fig. 2b).

Increased VCAM1 was mediated by NADPH oxidasederived ROS and promoted cell migration and angiogenesis

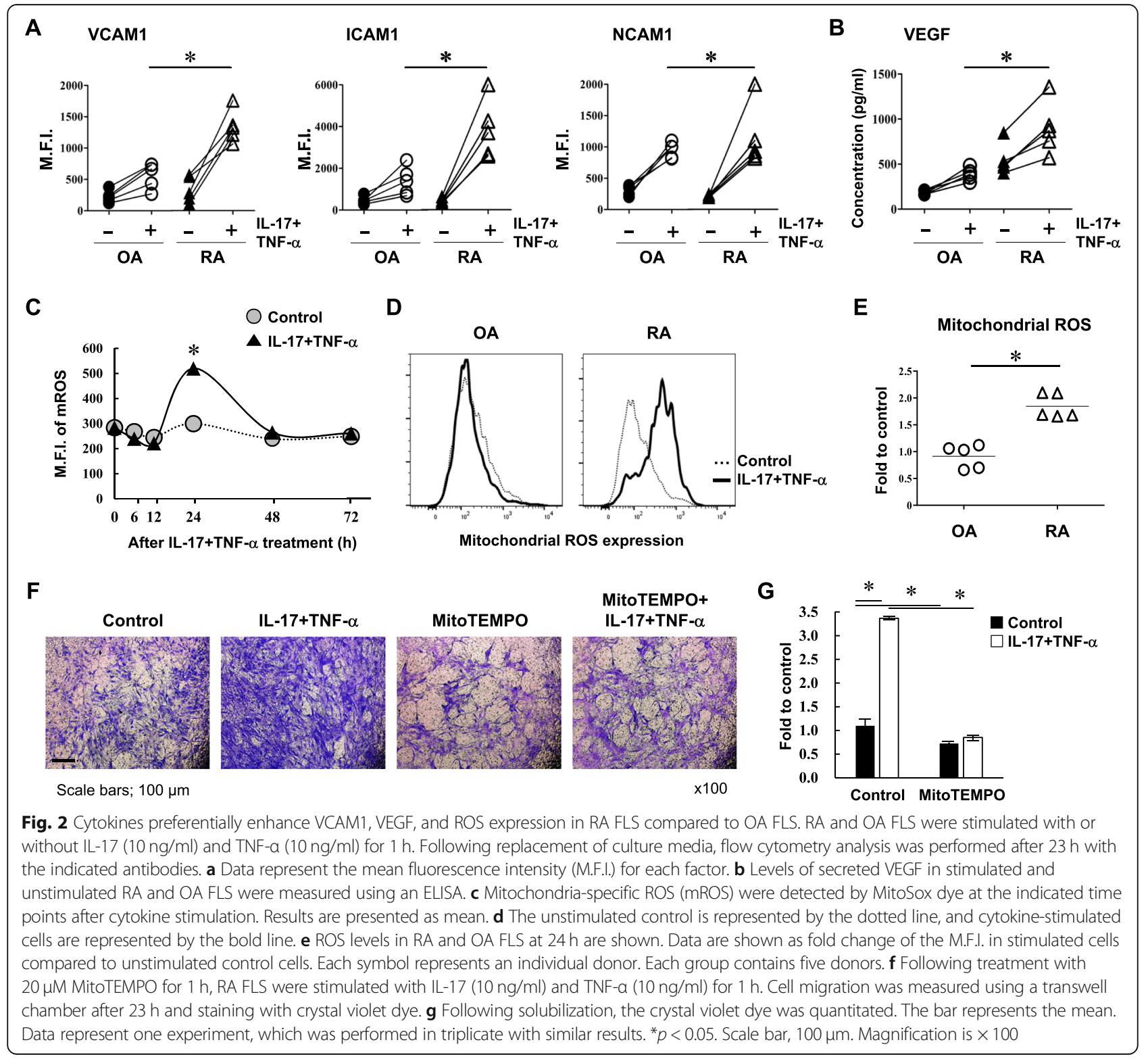


[22]. Therefore, we hypothesized that elevated ROS levels may mediate the enhanced migration and invasion observed in RA FLS following cytokine stimulation. Following incubation with IL-17 and TNF- $\alpha$, the levels of mitochondriaspecific ROS in RA FLS were significantly enhanced at $24 \mathrm{~h}$ compared to control unstimulated RA FLS (Fig. 2c). There was no difference after $48 \mathrm{~h}$. Next, intracellular ROS expression in RA and OA FLS was analyzed following IL-17 and TNF- $\alpha$ treatment for $24 \mathrm{~h}$. ROS levels were substantially upregulated in RA FLS following cytokine stimulation compared to levels in unstimulated RA FLS controls $(1.84 \pm$ 0.20 ), whereas intracellular ROS levels were not changed in OA FLS following cytokine stimulation $(0.91 \pm 0.19$; Fig. $2 \mathrm{~d}$, e). To determine more precisely the role of cytokines in controlling cell migration through mitochondrial specific ROS, we measured cytokine-induced RA FLS migration after treatment with MitoTEMPO mitochondria-targeted antioxidant. IL-17- and TNF- $\alpha$-mediated cell migration was significantly attenuated by MitoTEMPO pretreatment (Fig. 2f, g). Taken together, these results suggest that a differential increase in ROS induced by cytokines leads to the difference in migration and invasion between RA and OA FLS.

\section{Overexpression of NOX4 by IL-17 and TNF-a in RA FLS}

ROS generation is closely regulated by the NOX assembly system [23]. To determine whether NOX is involved in the differential expression of ROS in RA and OA, FLS were treated with IL-17 and TNF- $\alpha$ for $1 \mathrm{~h}$ and analyzed by real time PCR for NOX family gene expression. Among NOX isoforms, NOX4 and NOX2 expression was significantly enhanced in RA FLS (Fig. 3a). Expression of the NOX2/4binding proteins, $p 22 p h o x$ and $p 67 p h o x$, was also highly

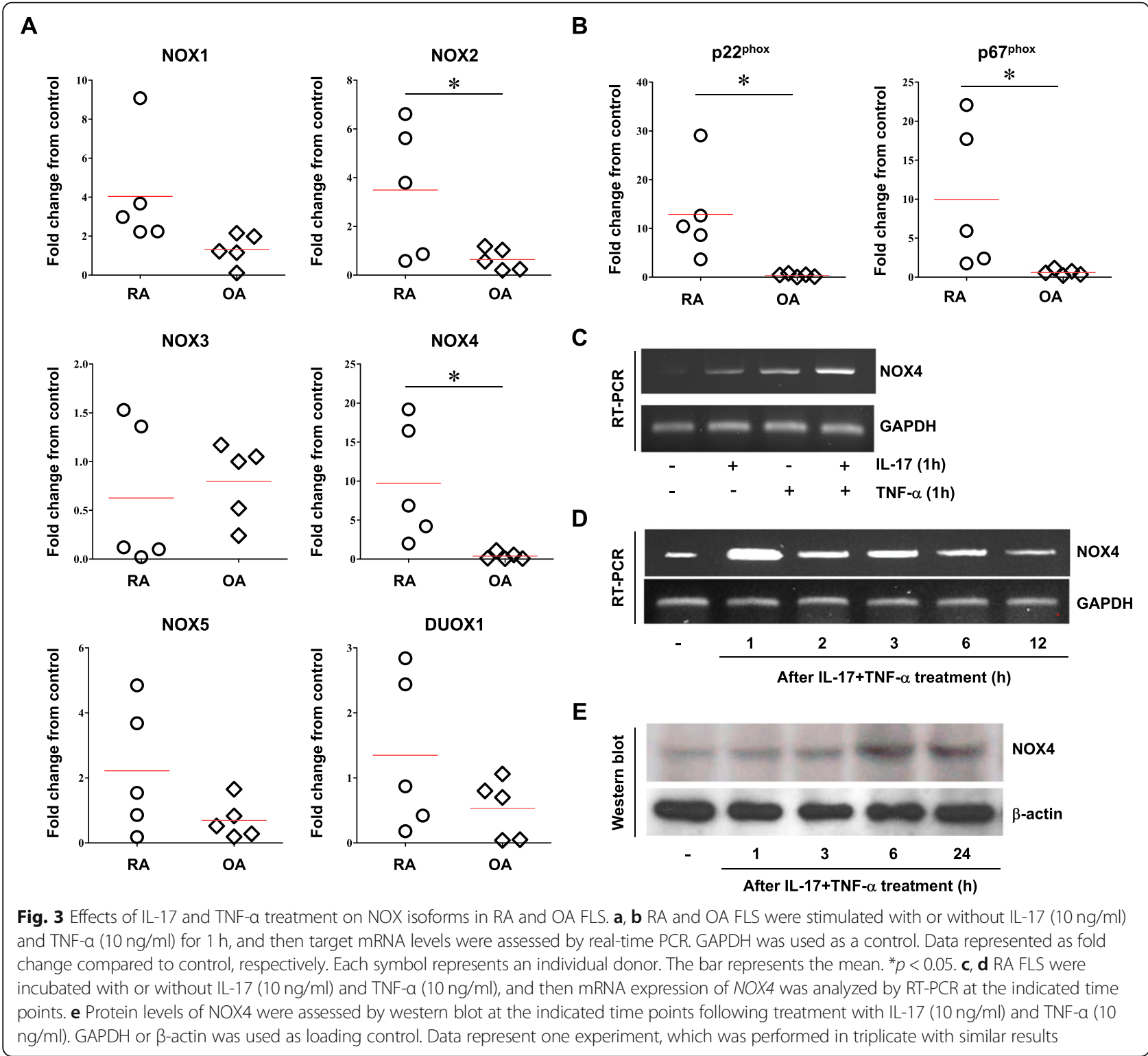


upregulated in RA FLS following IL-17 and TNF- $\alpha$ treatment (Fig. 3b). The more NOX2, NOX4, p22phos, and p67phos were expressed by cytokines, the higher levels of ROS were produced in individual RA FLS (supplementary data 1). After treatment with IL-17 and/or TNF- $\alpha$ for $1 \mathrm{~h}$, NOX4 mRNA level was examined. In accordance with cell migration tendency, combination of IL-17 and TNF- $\alpha$ markedly increased NOX4 expression in RA FLS (Fig. 3c). The increased mRNA expression of NOX4 peaked $1 \mathrm{~h}$ after cytokine stimulation in RA FLS (Fig. 3d). Following incubation of RA FLS with IL-17 and TNF- $\alpha$, NOX4 protein levels were markedly elevated for $6 \mathrm{~h}$ up to $24 \mathrm{~h}$ compared to unstimulated control FLS (Fig. 3e). These data showed that NOX4 may be a major contributor to the enhanced ROSmediated migration and invasion of FLS in RA.

\section{Decreased migration and invasion by NOX4 inhibition}

We next wanted to determine whether NOX4 is a critical regulator in IL-17- and TNF- $\alpha$-induced migration and invasion in RA. RA FLS were incubated with increasing doses of the NOX4-specific inhibitor GLX351322 for $1 \mathrm{~h}$, and then cells were treated with IL-17 and TNF- $\alpha$ for $1 \mathrm{~h}$. After $23 \mathrm{~h}$, the cytokine-induced ROS levels were substantially reduced by the NOX4 inhibitor in a dosedependent manner (Fig. 4a, b). Among the cytokineinduced adhesion molecules, only VCAM1 was distinctly decreased following NOX4 inhibition (Fig. 4c). Cell migration and VEGF secretion were also significantly reduced by NOX4 inhibition in RA FLS (Fig. 5a, b). When FLS were treated with NOX4-specific inhibitor alone, cell functions were not affected (data not shown).

To confirm the role of NOX4 in cell invasion, we reduced the mRNA levels of NOX4 in RA FLS using siRNA transfection (Fig. 5c). Following 24h, NOX4 silencing decreased NOX4 protein by 0.57 fold in western blot analysis. After verification of NOX4 silencing, RA FLS were incubated with IL-17 and TNF- $\alpha$ for $1 \mathrm{~h}$, and cell invasion was assessed using a Matrigel-coated transwell chamber assay. When RA FLS were transfected with control siRNA, IL-17 and TNF- $\alpha$ markedly enhanced the invasion capabilities of RA FLS; however, NOX4 knockdown suppressed the invasive ability of stimulated FLS compared with those treated with control siRNA (Fig. $5 d$, e). Despite IL-17 and TNF- $\alpha$ treatment, FLS invasion was inhibited compared to untreated controls in NOX4-silenced RA FLS. These findings demonstrate that

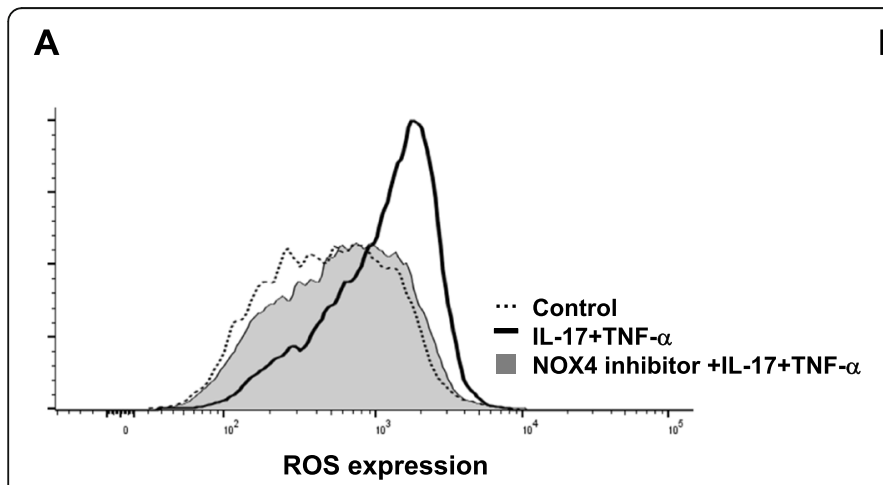

B
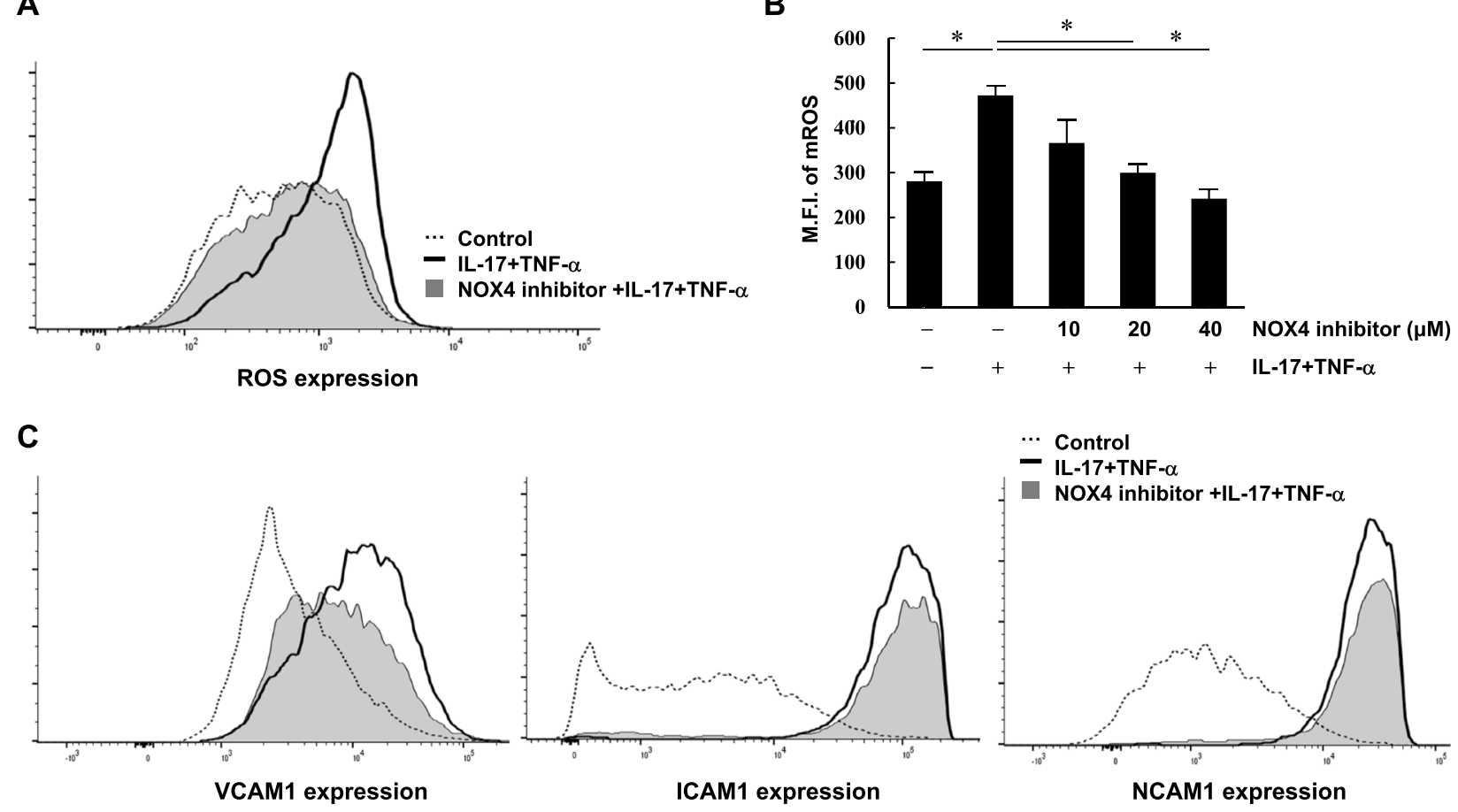

Fig. $4 \mathrm{IL}$-17- and TNF-a-induced ROS and VCAM1 are downregulated by NOX4-specific inhibition in RA FLS. RA FLS were pre-incubated with $40 \mathrm{\mu M}$ of NOX4 inhibitor GLX351322 for $1 \mathrm{~h}$, and then cells were stimulated with or without IL-17 (10 ng/ml) and TNF-a (10 ng/ml) for $1 \mathrm{~h}$. a After $23 \mathrm{~h}$, mitochondria-specific ROS was detected by MitoSox dye. The unstimulated control is shown as a dotted line, and cytokine stimulation is shown as a bold line. The gray-shaded area indicates treatment with both NOX4 inhibitor and cytokines. $\mathbf{b}$ ROS levels were quantitated in cells incubated with increasing amounts of NOX4 inhibitor and then stimulated with or without IL-17 and TNF-a. Data are shown as the mean fluorescence intensity (M.F.I.) \pm S.E.M. * $p<0.05$. c Flow cytometry analysis was performed using the indicated antibodies. Data represent one experiment, which was performed in triplicate with similar results 


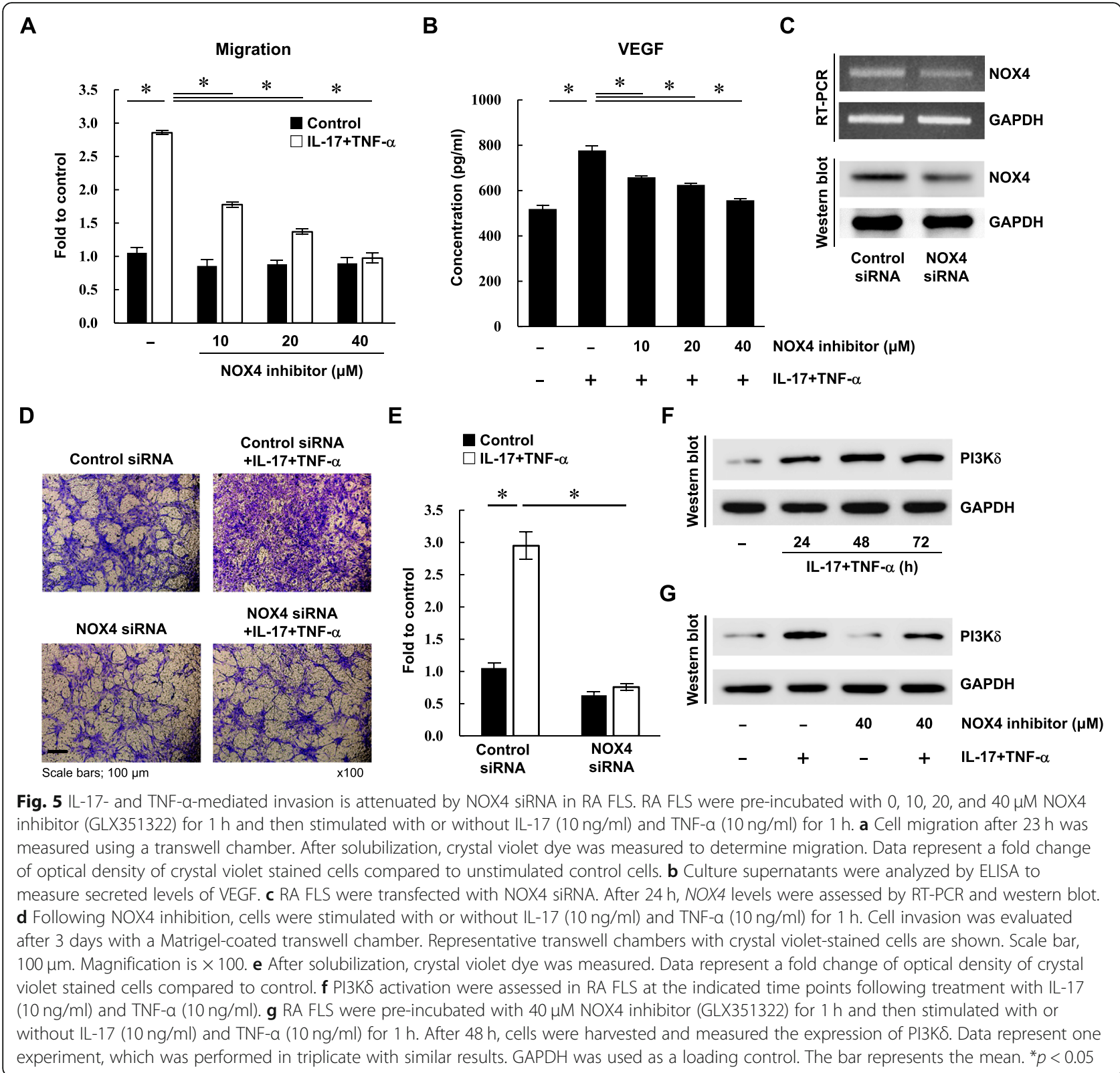

cytokine-induced migration and invasion are dependent on a NOX4-VCAM1-VEGF pathway.

In the study by Beatrix Bartok et al., phosphoinositide 3-kinase $\delta(\mathrm{PI} 3 \mathrm{~K} \delta$ ) played as a critical regulator in migration and invasion of synoviocytes in RA [24]. We hypothesized that PI3K $\delta$ might have a role in NOX4 mediated cell invasion. When RA FLS were stimulated with IL-17 and TNF- $\alpha$, the protein level of PI3K $\delta$ was markedly increased up to $72 \mathrm{~h}$ (Fig. 5f). On the other hand, NOX4 inhibitor GLX351322 attenuated cytokine-mediated PI3K $\delta$ activation (Fig. 5g). These data suggested that PI3K $\delta$ may contribute in NOX4-mediated cell migration and invasion in RA FLS.

\section{Discussion}

FLS are the major population in the synovium and play a critical role in arthritis pathogenesis. In this study, we investigated the effects of the arthritis-associated cytokines IL-17 and TNF- $\alpha$ on the migration and invasion of FLS. IL-17 and TNF- $\alpha$ are the primary focus in RA disease research, and combined blockade of both cytokines has been suggested as a novel therapy for patients who are unresponsive to selective TNF- $\alpha$ inhibition $[25,26]$. Here, we revealed that NOX4 mediated a differential response to IL-17 and TNF- $\alpha$ stimulation in RA FLS compared to OA FLS. Specifically, NOX4 was increased by cytokine exposure and was required for RA FLS migration and invasion via increased expression of VCAM1 
and VEGF. Our findings therefore highlight NOX4 as a potential treatment target in RA.

Interestingly, while RA FLS demonstrated a rapid and robust increase in migration and invasion following cytokine stimulation, FLS from OA donors showed little or no enhancement. The differential responses may be related to the different amounts of IL-17 and TNF- $\alpha$ in synovium. Indeed, IL-17 was detected at higher concentrations in RA synovium than in OA or control synovium $[27,28]$. Although migration and invasion in OA FLS did not change with cytokine stimulation for $1 \mathrm{~h}$, expression of VCAM1, ICAM1, NCAM1, and VEGF was increased 2-3-fold. Therefore, we concluded that the adhesion molecules and angiogenic factors were differentially regulated by these cytokines through a mechanism that is distinct from cell migration and invasion.

Next, we investigated whether IL-17 and TNF- $\alpha$ affected ROS levels in RA and OA FLS, because ROS have been shown to directly induce cell migration and invasion in the context of cancer [29]. Mitochondria-specific ROS expression was increased by cytokines in RA FLS but not OA FLS, and similar results were found for invasiveness. Our findings strongly suggest that IL-17 and TNF- $\alpha$ induce a differential increase in ROS that leads to the distinct invasion capabilities between RA and OA.

The increased intracellular ROS in FLS may negatively influence RA-associated synovium changes, such as immune cell activation and pro-inflammatory cytokine secretion, as well as invasion of FLS into bone [30, 31]. In relation to cell migration, ROS-generating enzymes in the NOX family have been suggested as therapeutic target molecules in various diseases, such as cardiovascular disease, autoimmune disease, and inflammation [32, 33]. It was shown that RA FLS exhibited aggressive features, such as hypoxia, invasion, and inflammation, which are similar to cancer [34]. NOX4 overexpression in human colorectal cancer was associated with poor prognosis and increased tumor migration and invasion [35]. In vascular inflammatory disease, NOX4 knockdown mediated a significant decrease in inflammation $[36,37]$. Although inhibition of excessive ROS has previously been suggested as an important target in RA treatment, few studies have investigated the role of NOX and RA FLS.

When mRNA expression in RA FLS was analyzed in response to IL-17 and TNF- $\alpha$ stimulation, NOX4 was increased most among the NOX family members. Following NOX4 inhibition in RA FLS, cytokine-induced ROS, VCAM1, VEGF, migration, and invasion were downregulated to levels observed for untreated controls. Together, these results indicate that IL-17- and TNF- $\alpha$ mediated NOX4 expression activates a ROS-VCAM1VEGF pathway that contributes to FLS migration and invasion in $R A$.
One limitation of this study is the use of ex vivo human FLS, which may not precisely reflect the in vivo response. Further study using an animal RA model is needed. In addition, the mRNA expression of NOX2 was also significantly increased in RA FLS, and therefore, additional study of the role of NOX2 in RA is warranted.

In conclusion, we revealed that NOX4 was upregulated in RA FLS following IL-17 and TNF- $\alpha$ stimulation, leading to aggressive migration and invasion via a ROSVCAM1-VEGF pathway. These findings suggest that NOX4 may be a critical factor in RA pathogenesis and that this enzyme may provide a therapeutic target for treatment of RA and other inflammatory diseases.

\section{Conclusions}

We investigated the effects of IL-17 and TNF- $\alpha$ on migration and invasion of FLS isolated from patients with RA and OA and further explored the effects of NOX4 inhibition in the pathogenesis of RA. Here, we revealed that NOX4 mediated a differential response to IL-17 and TNF- $\alpha$ stimulation in RA FLS compared to OA FLS. Specifically, NOX4 was increased by cytokine exposure and was required for RA FLS migration and invasion via increased expression of VCAM1 and VEGF. Our findings therefore highlight NOX4 as a potential treatment target in RA.

\section{Supplementary information}

Supplementary information accompanies this paper at https://doi.org/10. 1186/s13075-020-02204-0.

Additional file 1: Supplementary data 1. Correlative expressions among NOX isoforms in IL-17 and TNF-a stimulated RA FLS. RA FLS were stimulated with or without IL-17 $(10 \mathrm{ng} / \mathrm{ml})$ and TNF-a $(10 \mathrm{ng} / \mathrm{ml})$ for $1 \mathrm{~h}$, and then target mRNA levels were assessed by real-time PCR. GAPDH was used as a control. Data represented as fold change compared to control, respectively. Each symbol represents an individual donor.

\section{Abbreviations}

DAS28: 28-Joint Disease Activity Score; FITC: Fluorescein isothiocyanate; FLS: Fibroblast-like synoviocytes; HC: Healthy control subjects;

ICAM1: Intercellular adhesion molecule 1; IL-17: Interleukin 17; MFI: Mean fluorescence intensity; NADPH: Nicotinamide adenine dinucleotide phosphate; NCAM1: Neural cell adhesion molecule 1; NOX: Nicotinamide adenine dinucleotide phosphate oxidase; OA: Osteoarthritis; PBMC: Peripheral blood mononuclear cell; PE-PC5: Phycoerythrin-cyanine 5; PI3K

$\delta$ : Phosphoinositide 3-kinase $\delta$; RA: Rheumatoid arthritis; ROS: Reactive oxygen species; TNF-a: Tumor necrosis factor alpha; VCAM1: Vascular cell adhesion molecule 1; VEGF: Vascular endothelial growth factor

\section{Acknowledgements}

Not applicable

\section{Authors' contributions}

Conception and design: H-R. Lee, Su-Jin Yoo, and Seong Wook Kang; development of methodology: H-R. Lee, Jinhyun Kim, In Seol Yoo, and Chan Keol Park; acquisition of data: H-R. Lee and Su-Jin Yoo; analysis and interpretation of data: H-R. Lee, Su-Jin Yoo, Jinhyun Kim, In Seol Yoo, Chan Keol Park, and Seong Wook Kang; writing, review, and/or revision of the manuscript: $\mathrm{H}-\mathrm{R}$. Lee, Su-Jin Yoo, and Seong Wook Kang. The author(s) read and approved the final manuscript. 


\section{Funding}

This work was supported by Basic Science Research Program through the National Research Foundation of Korea (NRF) funded by the Ministry of Education (NRF-2016R1D1A1B03931637 and NRF-2019R111A1A01046493).

\section{Availability of data and materials}

The datasets used and analyzed during the current study are available from the corresponding author on reasonable request.

\section{Ethics approval and consent to participate}

This study was performed according to the recommendations of the Declaration of Helsinki and approved by the Institutional Review Board of Chungnam National University Hospital (CNUH 2015-10-052).

\section{Consent for publication}

Not applicable.

\section{Competing interests}

The authors have declared no conflicting interests.

Received: 9 January 2020 Accepted: 28 April 2020

\section{Published online: 15 May 2020}

\section{References}

1. Arnett FC, Edworthy SM, Bloch DA, McShane DJ, Fries JF, Cooper NS, Healey LA, Kaplan SR, Liang MH, Luthra HS, et al. The American Rheumatism Association 1987 revised criteria for the classification of rheumatoid arthritis. Arthritis Rheum. 1988;31(3):315-24.

2. Klareskog L, Catrina Al, Paget S. Rheumatoid arthritis. Lancet. 2009;373(9664): 659-72.

3. Mclnnes IB, Schett $G$. The pathogenesis of rheumatoid arthritis. N Engl J Med. 2011:365(23):2205-19.

4. Bartok B, Firestein GS. Fibroblast-like synoviocytes: key effector cells in rheumatoid arthritis. Immunol Rev. 2010;233(1):233-55.

5. Bustamante MF, Garcia-Carbonell R, Whisenant KD, Guma M. Fibroblast-like synoviocyte metabolism in the pathogenesis of rheumatoid arthritis. Arthritis Res Ther. 2017;19(1):110.

6. Phull AR, Nasir B, Haq IU, Kim SJ. Oxidative stress, consequences and ROS mediated cellular signaling in rheumatoid arthritis. Chem Biol Interact. 2018; 281:121-36.

7. Mateen S, Moin S, Khan AQ, Zafar A, Fatima N. Increased reactive oxygen species formation and oxidative stress in rheumatoid arthritis. PLoS One. 2016;11(4):e0152925.

8. Sena LA, Chandel NS. Physiological roles of mitochondrial reactive oxygen species. Mol Cell. 2012;48(2):158-67.

9. Boveris A, Chance B. The mitochondrial generation of hydrogen peroxide. General properties and effect of hyperbaric oxygen. Biochem J. 1973;134(3): 707-16.

10. Gorlach A, Brandes RP, Nguyen K, Amidi M, Dehghani F, Busse R. A gp91phox containing NADPH oxidase selectively expressed in endothelial cells is a major source of oxygen radical generation in the arterial wall. Circ Res. 2000:87(1):26-32.

11. Pendyala S, Gorshkova IA, Usatyuk PV, He D, Pennathur A, Lambeth JD, Thannickal VJ, Natarajan V. Role of Nox4 and Nox2 in hyperoxia-induced reactive oxygen species generation and migration of human lung endothelial cells. Antioxid Redox Signal. 2009;11(4):747-64.

12. Sun X, Wei J, Tang Y, Wang B, Zhang Y, Shi L, Guo J, Hu F, Li X. Leptininduced migration and angiogenesis in rheumatoid arthritis is mediated by reactive oxygen species. FEBS Open Bio. 2017;7(12):1899-908.

13. Chabaud M, Garnero P, Dayer JM, Guerne PA, Fossiez F, Miossec P. Contribution of interleukin 17 to synovium matrix destruction in rheumatoid arthritis. Cytokine. 2000;12(7):1092-9.

14. Xu T, Ying T, Wang L, Zhang XD, Wang $Y$, Kang L, Huang T, Cheng L, Wang $L$, Zhao Q. A native-like bispecific antibody suppresses the inflammatory cytokine response by simultaneously neutralizing tumor necrosis factor-alpha and interleukin-17A. Oncotarget. 2017:8(47): 81860-72.

15. Hueber AJ, Asquith DL, Miller AM, Reilly J, Kerr S, Leipe J, Melendez AJ, McInnes IB. Mast cells express IL-17A in rheumatoid arthritis synovium. J Immunol. 2010;184(7):3336-40.
16. Lefevre S, Knedla A, Tennie C, Kampmann A, Wunrau C, Dinser R, Korb A, Schnaker EM, Tarner IH, Robbins PD, et al. Synovial fibroblasts spread rheumatoid arthritis to unaffected joints. Nat Med. 2009;15(12): 1414-20.

17. Wluka AE, Ding C, Jones G, Cicuttini FM. The clinical correlates of articular cartilage defects in symptomatic knee osteoarthritis: a prospective study. Rheumatology (Oxford). 2005;44(10):1311-6.

18. Aletaha D, Neogi T, Silman AJ, Funovits J, Felson DT, Bingham CO 3rd, Birnbaum NS, Burmester GR, Bykerk VP, Cohen MD, et al. 2010 Rheumatoid arthritis classification criteria: an American College of Rheumatology/ European League Against Rheumatism collaborative initiative. Arthritis Rheum. 2010;62(9):2569-81.

19. Pap T, Muller-Ladner U, Gay RE, Gay S. Fibroblast biology. Role of synovial fibroblasts in the pathogenesis of rheumatoid arthritis. Arthritis Res. 2000; 2(5):361-7.

20. Qu F, Guilak F, Mauck RL. Cell migration: implications for repair and regeneration in joint disease. Nat Rev Rheumatol. 2019;15(3):167-79.

21. Hamilton JL, Nagao M, Levine BR, Chen D, Olsen BR, Im HJ. Targeting VEGF and its receptors for the treatment of osteoarthritis and associated pain. $J$ Bone Miner Res. 2016;31(5):911-24.

22. Dong A, Shen J, Zeng M, Campochiaro PA. Vascular cell-adhesion molecule1 plays a central role in the proangiogenic effects of oxidative stress. Proc Natl Acad Sci U S A. 2011;108(35):14614-9.

23. Segal BH, Leto TL, Gallin Il, Malech HL, Holland SM. Genetic, biochemical, and clinical features of chronic granulomatous disease. Medicine (Baltimore). 2000;79(3):170-200

24. Bartok B, Hammaker D, Firestein GS. Phosphoinositide 3-kinase delta regulates migration and invasion of synoviocytes in rheumatoid arthritis. J Immunol. 2014;192(5):2063-70.

25. Alzabin S, Abraham SM, Taher TE, Palfreeman A, Hull D, McNamee K, Jawad A, Pathan E, Kinderlerer A, Taylor PC, et al. Incomplete response of inflammatory arthritis to TNFalpha blockade is associated with the Th17 pathway. Ann Rheum Dis. 2012;71(10):1741-8.

26. Fischer JA, Hueber AJ, Wilson S, Galm M, Baum W, Kitson C, Auer J, Lorenz $\mathrm{SH}$, Moelleken J, Bader M, et al. Combined inhibition of tumor necrosis factor alpha and interleukin-17 as a therapeutic opportunity in rheumatoid arthritis: development and characterization of a novel bispecific antibody. Arthritis Rheumatol. 2015:67(1):51-62.

27. Honorati MC, Meliconi R, Pulsatelli L, Cane S, Frizziero L, Facchini A. High in vivo expression of interleukin-17 receptor in synovial endothelial cells and chondrocytes from arthritis patients. Rheumatology (Oxford). 2001;40(5): $522-7$.

28. Snelling SJ, Bas S, Puskas GJ, Dakin SG, Suva D, Finckh A, Gabay C, Hoffmeyer P, Carr AJ, Lubbeke A. Presence of IL-17 in synovial fluid identifies a potential inflammatory osteoarthritic phenotype. PLoS One. 2017;12(4):e0175109

29. Ushio-Fukai M, Nakamura Y. Reactive oxygen species and angiogenesis: NADPH oxidase as target for cancer therapy. Cancer Lett. 2008;266(1):37-52.

30. Yamamura Y, Gupta R, Morita Y, He X, Pai R, Endres J, Freiberg A, Chung K, Fox DA. Effector function of resting $T$ cells: activation of synovial fibroblasts. I Immunol. 2001;166(4):2270-5.

31. Tang $Y$, Wang B, Sun X, Li H, Ouyang X, Wei J, Dai B, Zhang Y, Li X. Rheumatoid arthritis fibroblast-like synoviocytes co-cultured with PBMC increased peripheral CD4(+) CXCR5(+) ICOS(+) T cell numbers. Clin Exp Immunol. 2017:190(3):384-93.

32. Vendrov AE, Vendrov KC, Smith A, Yuan J, Sumida A, Robidoux J, Runge MS, Madamanchi NR. NOX4 NADPH oxidase-dependent mitochondrial oxidative stress in aging-associated cardiovascular disease. Antioxid Redox Signal. 2015;23(18):1389-409.

33. Piera-Velazquez S, Jimenez SA. Role of cellular senescence and NOX4mediated oxidative stress in systemic sclerosis pathogenesis. Curr Rheumatol Rep. 2015:17(1):473.

34. Huber LC, Distler O, Tarner I, Gay RE, Gay S, Pap T. Synovial fibroblasts: key players in rheumatoid arthritis. Rheumatology (Oxford). 2006:45(6): 669-75

35. Lin XL, Yang L, Fu SW, Lin WF, Gao YJ, Chen HY, Ge ZZ. Overexpression of NOX4 predicts poor prognosis and promotes tumor progression in human colorectal cancer. Oncotarget. 2017:8(20):33586-600.

36. Zhao H, Zhang M, Zhou F, Cao W, Bi L, Xie Y, Yang Q, Wang S. Cinnamaldehyde ameliorates LPS-induced cardiac dysfunction via TLR4- 
NOX4 pathway: the regulation of autophagy and ROS production. J Mol Cell Cardiol. 2016;101:11-24.

37. Yu MH, Li X, Li Q, Mo SJ, Ni Y, Han F, Wang YB, Tu YX. SAA1 increases NOX4/ROS production to promote LPS-induced inflammation in vascular smooth muscle cells through activating p38MAPK/NF-kappaB pathway. BMC Mol Cell Biol. 2019;20(1):15.

\section{Publisher's Note}

Springer Nature remains neutral with regard to jurisdictional claims in published maps and institutional affiliations.

Ready to submit your research? Choose BMC and benefit from:

- fast, convenient online submission

- thorough peer review by experienced researchers in your field

- rapid publication on acceptance

- support for research data, including large and complex data types

- gold Open Access which fosters wider collaboration and increased citations

- maximum visibility for your research: over $100 \mathrm{M}$ website views per year

At $\mathrm{BMC}$, research is always in progress.

Learn more biomedcentral.com/submissions 